\title{
T. NAKAGAWA
}

\section{Combined replacement models}

Revue française d'automatique, d'informatique et de recherche opérationnelle. Recherche opérationnelle, tome 17, n 2 (1983), p. 193-203.

<http://www.numdam.org/item?id=RO_1983_17_2_193_0>

(C) AFCET, 1983, tous droits réservés.

L'accès aux archives de la revue « Revue française d'automatique, d'informatique et de recherche opérationnelle. Recherche opérationnelle » implique l'accord avec les conditions générales d'utilisation (http://www.numdam.org/ legal.php). Toute utilisation commerciale ou impression systématique est constitutive d'une infraction pénale. Toute copie ou impression de ce fichier doit contenir la présente mention de copyright.

\section{Numdam}

Article numérisé dans le cadre du programme

Numérisation de documents anciens mathématiques

http://www.numdam.org/ 


\title{
COMBINED REPLACEMENT MODELS (*)
}

\author{
by T. Nakagawa $\left({ }^{1}\right)$
}

\begin{abstract}
This paper summarizes ten replacement models which combine three basic replacements: (i) age replacement; (ii) block replacement; (iii) periodic replacement with minimal repair at failure. The expected cost rates of each model are derived, using the usual calculus method of probability. As an example, we give an optimum policy to minimize the expected cost rate of one model.
\end{abstract}

Keywords: Replacement; Three policies; Expected cost; Optimization.

Résumé. - Cet article résume dix modèles de renouvellement combinant: (i) âge de renouvellement; (ii) renouvellement par bloc; (iii) renouvellement périodique avec réparation minimale en cas de panne. Les taux moyens de coût de chaque modèle sont calculés en utilisant les méthodes probabilistes classiques. Comme exemple, nous donnons la politique optimale pour minimiser le taux moyen d'un des modeles.

\section{INTRODUCTION}

Failure of a unit during actual operation is sometimes costly or dangerous. It is important to replace an operating unit before its failure. Three replacement policies were defined and studied for an infinite time horizon by Barlow and Proschan [2]. Under these policies, we assume that replacement and repair times are negligible.

(i) Age replacement

A unit is replaced at scheduled time $T$ after its installation or at failure, whichever occurs first. The expected cost rate is:

$$
C_{1}(T)=\left[c_{1}+c_{2} F(T)\right] / \int_{0}^{T} \bar{F}(t) d t
$$

where $F(t)=$ distribution of the failure time of a unit, where $\bar{F} \equiv 1-F, c_{1}=$ cost of replacement, $c_{2}=$ additional cost of replacement for a failed unit.

(ii) Block replacement

A unit is replaced at scheduled times $k T(k=1,2, \ldots)$ and at failure.

(*) Received in November 1981.

(1) Department of Mathematics, Meijo University, Nagoya 468, Japan.

R.A.I.R.O. Recherche opérationnelle/Operations Research, 0399-0559/1983/193/\$ 5.00

(C) AFCET-Bordas-Dunod 
The expected cost rate is :

$$
C_{2}(T)=\left[c_{1}+c_{3} M(T)\right] / T,
$$

where $M(t)=$ expected number of failures during $(0, t], c_{3}=$ cost of replacement for each failed unit.

(iii) Periodic replacement

A unit is replaced at scheduled times $k T(k=1,2, \ldots)$. Minimal repair is made at failures between successive replacements, so that the failure rate of a unit remains undisturbed by any repair of failures. The expected cost rate is:

$$
C_{3}(T)=\left[c_{1}+c_{4} R(T)\right] / T
$$

where $R(t)=$ cumulative failure rate of the failure time distribution $F(t)$, i. e., $R(t) \equiv \int_{0}^{t} r(u) d u$ where $r(t)(\equiv f(t) / \bar{F}(t))$ is a failure rate and $f$ is a density of $F, c_{4}=$ cost of minimal repair for each failed unit.

Many authors studied modified or extended models of the above policies and discussed optimum policies; e.g., $[6,8,17,20]$ for age replacement, $[4,9,12,22]$ for block replacement, and $[3,10,14,24]$ for periodic replacement. Similarly, it is of great interest to consider combined models. For example, a unit is replaced at time $T$ or at $N$-th failure, whichever occurs first, where $(N-1)$-th previous failures are corrected with minimal repair [21]. The model corresponds to age replacement when $N=1$ and to periodic replacement when $N=\infty$. If there exists an $N^{*}\left(1<N^{*}<\infty\right)$ which minimizes the expected cost rate, this has a lower cost rate than two basic models.

This paper considers ten replacement models which combine age, block and periodic replacements, and obtains the expected cost rates of each model. It is difficult to discuss optimum policies for such models. As an example, we pick up only model 4 and derive optimum replacement times which minimize the expected cost rate.

\section{COMBINED POLICIES}

(1) The unit is replaced at scheduled time $T$ or at $N$-th failure, whichever occurs first, where $(N-1)$-th failed units are replaced by a new one. Then, the 
expected cost rate is easily given by:

$$
C_{12}(T, N)=\frac{c_{1}+c_{2} F^{(N)}(T)+c_{3} \sum_{j=1}^{N-1} F^{(j)}(T)}{\int_{0}^{T}\left[1-F^{(N)}(t)\right] d t},
$$

where $F^{(j)}(t)=j$-fold convolution of $F(t)$ with itself $(j=1,2, \ldots)$, and:

$$
F^{(0)}(t)=1 \quad \text { for } t \geqq 0, \quad 0 \quad \text { for } t<0 .
$$

This corresponds to age replacement when $N=1$ and to block replacement when $N=\infty$.

(2) The unit is replaced at each failure during $\left(0, T_{0}\right]$ and at scheduled time $T$ for $T \geqq T_{0}$. If the unit fails during $\left(T_{0}, T\right)$, it is replaced by a new unit before time $T$. Then, the probability that the unit fails in an interval $\left(T_{0}, T\right)$ is, from Ross ([19], p. 45),

$$
\operatorname{Pr}\left\{\gamma\left(T_{0}\right) \leqq T-T_{0}\right\}=F(T)-\int_{0}^{T_{0}} \bar{F}(T-t) d M(t),
$$

where $\gamma(t)=$ remaining life of the unit at time $t$ in a renewal process. The mean time to replacement after time $T_{0}$ is :

$$
\begin{aligned}
& \int_{T_{0}}^{T} t d_{t} \operatorname{Pr}\left\{\gamma\left(T_{0}\right) \leqq t-T_{0}\right\}+T \operatorname{Pr}\left\{\gamma\left(T_{0}\right)>T-T_{0}\right\} \\
&=T_{0}+\int_{T_{0}}^{T}\left[\bar{F}(t)+\int_{0}^{T_{0}} \bar{F}(t-u) d M(u)\right] d t .
\end{aligned}
$$

Thus, the expected cost rate is:

$$
C_{12}\left(T, T_{0}\right)=\frac{c_{1}+c_{2}\left[F(T)-\int_{0}^{T_{0}} \bar{F}(T-t) d M(t)\right]+c_{3} M\left(T_{0}\right)}{T_{0}+\int_{T_{0}}^{T}\left[\bar{F}(t)+\int_{0}^{T_{0}} \bar{F}(t-u) d M(u)\right] d t} .
$$


This corresponds to age replacement when $T_{0}=0$ and to block replacement when $T=T_{0}$.

(3) The unit is replaced at time $T$ or at $N$-th failure, whichever occurs first, after its installation. The unit undergoes only minimal repair at failures between replacements. Then, the expected number of failures before replacement is, from Morimura [10],

$$
\sum_{j=0}^{N-1} j p_{j}(T)+(N-1) \int_{0}^{T} p_{N-1}(t) r(t) d t=N-1-\sum_{j=0}^{N-1}(N-1-j) p_{j}(T),
$$

where $p_{j}(t)=\left\{[R(t)]^{j} / j !\right\} e^{-R(t)}$, which represents the probability that $j$ failures occur in $(0, t]$. The mean time to replacement is:

$$
\int_{0}^{T} t p_{N-1}(t) r(t) d t+T \sum_{j=0}^{N-1} p_{j}(T)=\sum_{j=0}^{N-1} \int_{0}^{T} p_{j}(t) d t .
$$

Then, the expected cost rate is:

$$
C_{13}(T, N)=\frac{c_{1}+c_{2} \sum_{j=N}^{\infty} p_{j}(T)+c_{4}\left[N-1-\sum_{j=0}^{N-1}(N-1-j) p_{j}(T)\right]}{\sum_{j=0}^{N-1} \int_{0}^{T} p_{j}(t) d t} .
$$

This corresponds to age replacement when $N=1$ and to periodic replacement when $N=\infty$. In particular, when $T=\infty$, i. e., the unit is replaced only at $N$-th failure, the optimum policy was derived by Morimura [10] and Nakagawa [16], and Park [18] in Weibull case.

(4) The unit undergoes only minimal repair at failures during $\left(0, T_{0}\right]$. If the unit fails in $\left(T_{0}, T\right)$, it is replaced by a new unit, while if the unit does not fail in $\left(T_{0}, T\right)$, it is replaced at scheduled time $T$. The mean time to replacement is :

$$
\frac{1}{\bar{F}\left(T_{0}\right)} \int_{T_{0}}^{T} t d F(t)+T \frac{\bar{F}(T)}{\bar{F}\left(T_{0}\right)}=T_{0}+\frac{1}{\bar{F}\left(T_{0}\right)} \int_{T_{0}}^{T} \bar{F}(t) d t .
$$

Thus, the expected cost rate is:

$$
C_{13}\left(T, T_{0}\right)=\frac{c_{1}+c_{2}\left\{\left[F(T)-F\left(T_{0}\right)\right] / \bar{F}\left(T_{0}\right)\right\}+c_{4} R\left(T_{0}\right)}{T_{0}+\int_{T_{0}}^{T} \bar{F}(t) d t / \bar{F}\left(T_{0}\right)} .
$$

R.A.I.R.O. Recherche opérationnelle/Operations Research 
This corresponds to age replacement when $T_{0}=0$ and to periodic replacement when $T=T_{0}$. The optimum policy was discussed by Tahara and Nishida [21], and Nakagawa [14] when $T$ is constant.

(5) Consider the unit with two types of failures [3]. When the unit fails, type 1 failure occurs with probability $\alpha(0 \leqq \alpha \leqq 1)$ and is removed by minimal repair, and type 2 failure occurs with probability $\beta(\equiv 1-\alpha)$ and is removed by replacement. The unit is replaced at time $T$ or at time of type 2 failure, whichever occurs first. The expected number of type 1 failures before replacement is :

$$
\sum_{j=0}^{\infty} j \alpha^{j} p_{j}(T)+\sum_{j=0}^{\infty} j \alpha^{j} \beta \int_{0}^{T} p_{j}(t) r(t) d t=(\alpha / \beta) F_{\beta}(T),
$$

where $F_{\beta}(t) \equiv 1-e^{-\beta R(t)}$. The mean time to replacement is:

$$
T \sum_{j=0}^{\infty} \alpha^{j} p_{j}(T)+\sum_{j=0}^{\infty} \alpha^{j} \beta \int_{0}^{T} t p_{j}(t) r(t) d t=\int_{0}^{T} \vec{F}_{\beta}(t) d t .
$$

Thus, the expected cost rate is:

$$
C_{13}(T ; \alpha)=\frac{c_{1}+c_{2} F_{\beta}(T)+c_{4}(\alpha / \beta) F_{\beta}(T)}{\int_{0}^{T} \bar{F}_{\beta}(t) d t} .
$$

This becomes the same age replacement model by replacing $F_{\beta}(t)$ and $c_{2}+c_{4}(\alpha / \beta)$ into $F(t)$ and $c_{2}$, respectively. Further, this corresponds to age replacement when $\alpha=0$ and to periodic replacement when $\alpha=1$.

(6) Consider a system with two types of units which operate statistical independently. When unit 1 fails, it undergoes minimal repair and begins to operate again. When unit 2 fails, the system is replaced. Unit 1 has a failure time distribution $G(t)$ with failure rate $h(t)$, i. e., $h(t) \equiv g(t) / \bar{G}(t)$, where $g$ is a density of $G$, and unit 2 has $F(t)$. Then, the expected cost rate is easily given by:

$$
C_{13}(T ; G)=\frac{c_{1}+c_{2} F(T)+c_{4} \int_{0}^{T} \bar{F}(t) h(t) d t}{\int_{0}^{T} \bar{F}(t) d t} .
$$

vol. $17, \mathrm{n}^{\circ} 2$, mai 1983 
This corresponds to age replacement when $G(t) \equiv 0$ and to periodic replacement when $F(t) \equiv 0$.

(7) The unit is replaced at failures during $\left(0, T_{0}\right]$ and at scheduled time $T$ for $T \geqq T_{0}$. If the unit fails during $\left(T_{0}, T\right)$, it undergoes minimal repair. The expected number of failures during $\left(T_{0}, T\right)$ is:

$$
\begin{aligned}
& \int_{0}^{T_{0}}\left[\int_{T_{0}}^{T} r(t-u) d t\right] d_{u} \operatorname{Pr}\left\{\delta\left(T_{0}\right) \leqq T_{0}-u\right\} \\
& \quad=\bar{F}\left(T_{0}\right)\left[R(T)-R\left(T_{0}\right)\right]+\int_{0}^{T_{0}}\left[R(T-u)-R\left(T_{0}-u\right)\right] \bar{F}\left(T_{0}-u\right) d M(u),
\end{aligned}
$$

where $\delta(t)=$ age of the unit at time $t$ in a renewal process. Thus, the expected cost rate is, from [12],

$$
C_{23}\left(T, T_{0}\right)=\left\{\begin{array}{l}
c_{1}+c_{3} M\left(T_{0}\right)+c_{4}\left\{\bar{F}\left(T_{0}\right)\left[R(T)-R\left(T_{0}\right)\right]\right. \\
\left.+\int_{0}^{T_{0}}\left[R(T-u)-R\left(T_{0}-u\right)\right] \bar{F}\left(T_{0}-u\right) d M(u)\right\}
\end{array}\right\}
$$

This corresponds to periodic replacement when $T_{0}=0$ and to block replacement when $T=T_{0}$.

(8) In periodic replacement, we have assumed that the failure rate of an operating unit remains undisturbed by any repair of failures. Suppose that the age of the unit after minimal repair becomes at $(a \geqq 0)$ when it was $t$ before failure. The expected number of failures during $(0, T]$ is, from [15],

$$
\begin{array}{r}
R(T ; a)=\sum_{j=1}^{\infty} \int_{t_{1}<t_{2}<\ldots<t_{j} \leqq T} \int \frac{f\left(a t_{1}+t_{2}-t_{1}\right)}{\bar{F}\left(a t_{1}\right)} \frac{f\left[a^{2} t_{1}+a\left(t_{2}-t_{1}\right)+t_{3}-t_{2}\right]}{\bar{F}\left[a^{2} t_{1}+a\left(t_{2}-t_{1}\right)\right]} \\
\ldots \frac{f\left[a^{j-1} t_{1}+a^{j-2}\left(t_{2}-t_{1}\right)+\ldots+a\left(t_{j-1}-t_{j-2}\right)+t_{j}-t_{j-1}\right]}{\bar{F}\left[a^{j-1} t_{1}+a^{j-2}\left(t_{2}-t_{1}\right)+\ldots+a\left(t_{j-1}-t_{j-2}\right)\right]} d t_{1} d t_{2} \ldots d t_{j}
\end{array}
$$

The expected cost rate is:

$$
C_{23}(T ; a)=\left[c_{1}+c_{4} R(T ; a)\right] / T .
$$

R.A.I.R.O. Recherche opérationnelle/Operations Research 
Noting that $R(T ; 0)=M(T)$ and $R(T ; 1)=R(T)$, we easily see that this corresponds to block replacement when $a=0$ and to periodic replacement when $a=1$. If $a<1$ then the unit is younger at each minimal repair and if $a>1$ then it is worce than before failure.

(9) Consider the replacement model of a cumulative damage model [11, 23]: Assume that random variables $X_{j}(j=1,2, \ldots)$ are associated with a sequence of inter-arrival times between successive shocks, and random variables $W_{j}(j=1,2, \ldots)$ denote the amount of damage produced by the $j$-th shock. It is assumed that $\left\{W_{j}\right\}$ are non-negative, independent and identically distributed, and $W_{j}$ is independent of $X_{i}(i \neq j)$. The unit fails only when the total amount of damage exceeds a failure level $K$.

Suppose that $\operatorname{Pr}\left\{X_{j} \leqq t\right\} \equiv F(t)$ and $\operatorname{Pr}\left\{W_{j} \leqq x\right\} \equiv G(x)(j=1,2, \ldots)$. The unit is replaced at scheduled time $T$ or at failure, whichever occurs first. Then, the probability that the unit is replaced at failure is:

$$
\sum_{j=1}^{\infty} F^{(j)}(T)\left[G^{(j-1)}(K)-G^{(j)}(K)\right]
$$

and the expected number of shocks before replacement is:

$$
\begin{aligned}
& \sum_{j=1}^{\infty}(j-1) F^{(j)}(T)\left[G^{(j-1)}(K)-G^{(j)}(K)\right] \\
& \quad+\sum_{j=1}^{\infty} j G^{(j)}(K)\left[F^{(j)}(T)-F^{(j+1)}(T)\right]=\sum_{j=1}^{\infty} F^{(j)}(T) G^{(j)}(K) .
\end{aligned}
$$

The mean time to replacement is:

$$
\begin{aligned}
& \sum_{j=1}^{\infty}\left[G^{(j-1)}(K)-G^{(j)}(K)\right] \int_{0}^{T} t d F^{(j)}(t) \\
& +T \sum_{j=0}^{\infty} G^{(j)}(K)\left[F^{(j)}(T)-F^{(j+1)}(T)\right] \\
& \quad=\sum_{j=1}^{\infty}\left[G^{(j-1)}(K)-G^{(j)}(K)\right] \int_{0}^{T}\left[1-F^{(j)}(t)\right] d t
\end{aligned}
$$

vol. $17, \mathrm{n}^{\circ} 2$, mai 1983 
Thus, the expected cost rate is:

$$
C_{12}(T ; K)=\frac{c_{1}+c_{2} \sum_{j=1}^{\infty} F^{(j)}(T)\left[G^{(j-1)}(K)-G^{(j)}(K)\right]+c_{3} \sum_{j=1}^{\infty} F^{(j)}(T) G^{(j)}(K)}{\sum_{j=1}^{\infty}\left[G^{(j-1)}(K)-G^{(j)}(K)\right] \int_{0}^{T}\left[1-F^{(j)}(t)\right] d t},
$$

where $c_{3}=$ cost suffered for one schock. This corresponds to age replacement when $K=0$ and to block replacement when $K=\infty$.

(10) In model 9, we assume that each shock occurs in a non-homogeneous Poisson process (e. g., see Çinlar [5], p. 97), i. e.,

$$
\operatorname{Pr}\left\{X_{1}+X_{2}+\ldots+X_{j} \leqq t\right\}=\sum_{n=j}^{\infty} p_{n}(t) .
$$

In a similar way of obtaining (12), the expected cost rate is:

$$
C_{13}(T ; K)=\frac{c_{1}+c_{2} \sum_{j=1}^{\infty} p_{j}(T)\left[1-G^{(j)}(K)\right]+c_{3} \sum_{j=1}^{\infty} p_{j}(T) \sum_{n=1}^{j} G^{(n)}(K)}{\sum_{j=1}^{\infty}\left[G^{(j-1)}(K)-G^{(j)}(K)\right] \sum_{n=0}^{j-1} \int_{0}^{T} p_{n}(t) d t} .
$$

This corresponds to age replacement when $K=0$ and to periodic replacement when $K=\infty$. Further, note that models 9 and 10 become models 1 and 3, respectively, in particular cases of $G^{(j)}(K)=1$ for $j \leqq K, 0$ for $j>K$ and $K=N-1$.

\section{OPTIMUM POLICY}

Almost all models considered here become a problem of minimizing an objective function with two independent variables, which extends three basic replacement problems. It is very difficult to discuss optimum policies for such models. As an example, we take up an optimization problem which minimizes the expected cost rate $C_{13}\left(T, T_{0}\right)$ of model 4. Tahara and Nishida [21] and Adachi and Kodama [1] tried to obtain optimum times $T_{\delta}^{*}$ and $T^{*}$, however, the proof was partially incomplete and troublesome to understand.

We seek optimum replacement times $T_{0}^{*}$ and $T^{*}$ which minimize $C_{13}\left(T, T_{0}\right)$ in (7). Suppose that the failure rate $r(t)$ is strictly increasing to

R.A.I.R.O. Recherche opérationnelle/Operations Research 
infinity and differentiable. Then, differentiating $C_{13}\left(T, T_{0}\right)$ with $T$ and $T_{0}$ and setting them equal to zero, respectively, we have:

$$
\begin{aligned}
& {\left[r(T) \int_{T_{0}}^{T} \bar{F}(t) d t+\bar{F}(T)\right] / \bar{F}\left(T_{0}\right)=c_{4} / c_{2},} \\
& c_{2} T_{0} r(T)-c_{4} R\left(T_{0}\right)=c_{1}+c_{2}-c_{4} .
\end{aligned}
$$

A necessary condition that finite $T$ and $T_{0}$ minimize $C_{13}\left(T, T_{0}\right)$ are that they satisfy (14) and (15).

(i) Suppose that $c_{2}<c_{4}<c_{1}+c_{2}$. Letting:

$$
q\left(T ; T_{0}\right) \equiv\left[r(T) \int_{T_{0}}^{T} \bar{F}(t) d t+\bar{F}(T)\right] / \bar{F}\left(T_{0}\right)
$$

we evidently have:

$q\left(T_{0} ; T_{0}\right)=1<c_{4} / c_{2}$, $\lim _{T \rightarrow \infty} q\left(T ; T_{0}\right)=\infty$,

$$
d q\left(T ; T_{0}\right) / d T=r^{\prime}(T) \int_{T_{0}}^{T} \bar{F}(t) d t / \bar{F}\left(T_{0}\right)>0
$$

Thus, there exists a finite and unique $T^{*}\left(T_{0}<T^{*}<\infty\right)$ which satisfies (14) for a fixed $T_{0}$. Further,

$$
\frac{d q\left(T ; T_{0}\right)}{d T_{0}}=-r(T)+\frac{r\left(T_{0}\right)}{\bar{F}\left(T_{0}\right)}\left[r(T) \int_{T_{0}}^{T} \bar{F}(t) d t+\bar{F}(T)\right]<0,
$$

since $r\left(T_{0}\right)<\left[F(T)-F\left(T_{0}\right)\right] / \int_{T_{0}}^{T} \bar{F}(t) d t$ for $T>T_{0}$ from the assumption that $r(t)$ is strictly increasing. This implies that $T^{*}$ is an increasing function of $T_{0}$.

Next, prove that a solution $T_{0}^{*}$ to (15) exists and is unique, when $T^{*}\left(T_{0}\right)$ is given by a function of $T_{0}$ from (14). First, noting that $r(T) / r\left(T_{0}\right)>q\left(T ; T_{0}\right)$ for $0 \leqq T_{0}<T<\infty$ from (16), we have the inequality;

$$
r\left(T^{*}\left(T_{0}\right)\right) / r\left(T_{0}\right)>c_{4} / c_{2} .
$$

vol. $17, \mathrm{n}^{\circ} 2$, mai 1983 
Differentiating the left-hand side of (15) with $T_{0}$ and recalling that $T^{*}\left(T_{0}\right)$ is an increasing function of $T_{0}$, we have:

$$
c_{2} r\left(T^{*}\left(T_{0}\right)\right)-c_{4} r\left(T_{0}\right)+c_{2} T_{0} r^{\prime}\left(T^{*}\left(T_{0}\right)\right)\left[T^{*}\left(T_{0}\right)\right]^{\prime}>0 .
$$

Further, for some $\widetilde{T}_{0}<T_{0}$,

$$
c_{2} T_{0} r\left(T^{*}\left(T_{0}\right)\right)-c_{4} R\left(T_{0}\right)>c_{2} \widetilde{T}_{0} r\left(T^{*}\left(T_{0}\right)\right)-c_{4} R\left(\widetilde{T}_{0}\right) \rightarrow \infty \text { as } T_{0} \rightarrow \infty,
$$

because, in this case, $T^{*}\left(T_{0}\right) \rightarrow \infty$. Therefore, the left-hand side of (15) is strictly increasing from 0 to infinity, and hence, there exists a finite and unique $T_{0}^{*}$ which satisfies (15).

(ii) If $c_{4} \geqq c_{1}+c_{2}$ then $T_{0}^{*}=0$ from (15) and the model becomes age replacement.

(iii) If $c_{4} \leqq c_{2}$ then $T^{*}=T_{0}$ from (14) and the model becomes periodic replacement.

From the above results, if $c_{2}<c_{4}<c_{1}+c_{2}$ then model 4 has a lower cost rate than two basic modeis, and finite optimum times $T_{\delta}^{*}$ and $T^{*}\left(0<T_{0}^{*}<T^{*}<\infty\right)$ are given by the unique solutions of two equations (14) and (15).

\section{CONCLUSIONS}

We have considered ten replacement models for an infinite time horizon, which combine three basic replacements. As further problems, these models would offer interesting topics to reliability theoreticians. However, it is very difficult to discuss optimum policies for such models. One method of obtaining the optimum policy for model 4 could be helpful in solving a problem of minimizing an objective function with two variables.

\section{REFERENCES}

1. K. Adachi and M. Kodama, On Some Minimal Repair Model, Microelectron. Reliability, Vol. 20, 1980, pp. 265-271.

2. R. E. Barlow and F. Proschan, Math. Theory of Reliability, John Wiley and Sons, Inc., 1965.

3. F. Beichelt and K. Fischer, General Failure Model Applied to Preventive Maintenance Policies, I.E.E.E. Trans. on Reliability, Vol. R-29, 1980, pp. 39-41.

4. M. Berg and B. Epstern, A Modified Block Replacement Policy, Naval Res. Log. Q., Vol. 23, 1976, pp. 15-24.

5. E. ÇrnLar, Introduction to Stochastic Processes, Prentice Hall, 1975.

R.A.I.R.O. Recherche opérationnelle/Operations Research 
6. R. Clêroux and M. Hanscom, Age Replacement with Adjustment and Depreciation Costs and Interest Charges, Technometrics, Vol. 16, 1974, pp. 235-239.

7. D. R. Cox, Renewal Theory, Methuen, London, 1962.

8. P. C. I. Crookes, Replacement Strategies, Operational Res. Q., Vol. 14, 1963, pp. 167-184.

9. V. P. Marathe and K. P. K. Nair, Multistage Planned Replacement Strategies, Operations Res., Vol. 14, 1966, pp. 874-887.

10. H. Morimura, On Some Preventive Maintenance Policies for IFR, J. Operations Res. of Japan, Vol. 12, 1970, pp. 94-124.

11. T. Nakagawa, On a Replacement Problem of a Cumulative Damage Model, Operational Res. Q., Vol. 27, 1976, pp. 895-900.

12. T. NaKagawa, A Summary of Block Replacement Policies, R.A.I.R.O., Vol. 13, 1979 , pp. 351-361.

13. T. Nakagawa, A Summary of Imperfect Preventive Maintenance Policies with Minimal Repair, R.A.I.R.O., Vol. 14, 1980, pp. 249-255.

14. T. Nakagawa, Modified Periodic Replacement with Minimal Repair at Failure, I.E.E.E. Trans. Reliability, Vol. R-30, 1981, pp. 165-168.

15. T. Naxagawa, A Summary of Periodic Replacement with Minimal Repair at Failure, J. Operations Res. of Japan, Vol. 24, 1981, pp. 213-227.

16. T. Nakagawa, Generalized Models for Determining Optimal Number of Minimal Repairs before Replacement, J. Operations Res. of Japan, Vol. 24, 1981, pp. 325-337.

17. T. Nakagawa and S. Osakı, Optimum Replacement Policies with Delay, J. Appl. Prob., Vol. 11, 1974, pp. 102-110.

18. K. S. PARKs, Optimal Number of Minimal Repairs before Replacement, I.E.E.E. Trans. Reliability, Vol. R-28, 1979, pp. 137-140.

19. S. M. Ross, Applied Probability Models with Optimization Applications, HoldenDay, 1970.

20. R. L. Scheaffer, Optimum Age Replacement Policies with an Increasing Cost Factor, Technometrics, Vol. 13, 1971, pp. 139-144.

21. A. TAhara and T. Nishida, Optimal Replacement Policy for Minimal Repair Model, J. Operations Res. of Japan, Vol. 18, 1975, pp. 113-124.

22. T. TANGo, A Modified Block Replacement Policy Using Less Reliable Items, I.E.E.E. Trans. Reliability, Vol. R-28, 1979, pp. 400-401.

23. H. M. TAYLoR, Optimal Replacement under Additive Damage and Other Failure Models, Naval Res. Log. Q., Vol. 22, 1975, pp. 1-18.

24. C. Tilquin and R. Cléroux, Periodic Replacement with Minimal Repair at Failure and Adjustment Costs, Naval Res. Log. Q., Vol. 22, 1975, pp. 243-254. 